\title{
AMIZADE POLÍTICA PELO CUIDADO COM O MUNDO: SOBRE POLÍTICA E RESPONSABILIDADE NA OBRA DE HANNAH ARENDT*
}

\author{
Political Friendship by caring for the world: on politics \\ and responsibility in the work of Hannah Arendt
}

\author{
Wolfgang Heuer**
}

\begin{abstract}
RESUMO
O pensamento de Arendt é baseado na experiência do Totalitarismo, na completa destruição da política, no espaço inter-pessoal, na humanidade propriamente dita e na conclusão na qual nossa civilização é inerentemente frágil. Conseqüentemente, Arendt desenvolveu uma nova definição de política e seus fenômenos a partir de uma perspectiva de uma pluralidade interdependete, excluindo todos os aspectos de violência e soberania de estado. Suas percepções nos permite, ainda hoje, um melhor entendimento da fraqueza de governos assumidos como fortes, como os exemplos dos EUA ou da Venezuela, distinguindo entre os hábitos de líderes fortes e a ação política de cidadãos responsáveis, pensado na tradição aristotélica de amizade pública.
\end{abstract}

Palavras-chave: Hannah Arendt; política; amizade.

\begin{abstract}
Arendt's thinking is based on the experience of Totalitarianism, the complete destruction of politics, the interpersonal space and humanity itself and the conclusion that our civilization is inherently fragile. Consequently, Arendt developed a new definition of politics and its phenomena from the perspective of an interdependent plurality excluding all aspects of violence and sovereignty. Her insights allow us today a better understanding of the weakness of assumed strong

* Tradução de Marion Brepohl, professora do Departamento de História da Universidade

** Professor de Ciências Políticas da Universidade Livre de Berlin - Editor da revista Hannah
\end{abstract} Federal do Paraná e Bolsista do CNPq. Arendt Newsletter 
governments like that of the US or of Venezuela distinguishing between the habits of strong leaders and the political action of responsable citizens in the tradition of Aristoteles' public friendship.

Keywords: Hannah Arendt; politics; friendship.

O que significa amizade política? Seguramente não é a amizade de políticos, empregados estatais e empresários implicados em negócios corruptos, porque o crime poupa a luz do público. Amizade política, ao contrário, significa uma amizade no espaço público. Significa, por exemplo, somente num sentido restrito, a amizade entre o chanceler alemão Helmut Kohl e o presidente francês François Mitterand, porque serviu à reconciliação entre alemães e franceses, terminando com a inimizade hereditária destes dois países em virtude das três guerras ocorridas no intervelao de tempo que se estende de 1870 a 1945 . Mas ela não tematizou a amizade política como ação ativa e responsável da cidadania. E seguramente não siginifica a "amizade" entre o chanceler alemão Gerhard Schröder e o presidente russo Vladimir Putin, porque esta se parece mais com uma cumplicidade, uma amizade entre homens.

Amizade política pelo cuidado do mundo significa ser consciente da responsabilidade comum pela comunidade, definir-se como cidadão político e não comoum sujeito de consumo e defender a civilização da sociedade com seus valores de liberade e justiça e de engajar-se para a sua realização.

Tal atitude em nosso mundo é rara e por isso, quando ocorre, assume sempre um caráter de exemplaridade. A esses exemplos pertencem os mais de 1000 membros de empresas do Instituto Ethos em São Paulo, comprometidos com a responsabilidade social, ou o novo movimento Nossa São Paulo, dedicado a fazer de indivíduos cidadãos, no sentido de participação em discussões sobre o bem comum:

Outra Cidade, calcado no espírito de pertencimento e transformação, pretende, por sua abrangência, representatividade, credibilidade, comprometimento e eficácia, construir uma força política, social e econômica capaz de comprometer 
a sociedade e sucessivos governos com uma agenda e um conjunto de metas, visando oferecer uma melhor qualidade de vida para todos os habitantes da cidade. ${ }^{1}$

Neste contexto o "cuidado pelo mundo" não é um pathos a pretender insistir na ênfase à amizade pública, mas uma necessidade que aparece, nos escritos de Hannah Arendt, quando ela antepõe totaltiarismo e liberdadade, acosmismo e mundanidade.

Seu pensamento parte da experiência mesma do totalitarismo, cuja análise a leva a concluir se tratar de uma nova forma de dominação, baseada na mobilização das massas e na eliminação da distinção tradicional entre dominantes e dominados. Assim foi possível o fenômeno da chamada banalidade do mal - a discrepância entre a atitude corriqueira de um burocrata e a monstruosidade de seus crimes, um fenômeno inquietante, uma vez que, pessoas normais tornam-se aí, assassinos em massa. ${ }^{2}$ Este "contexto orgânico", como foi denominado pelo escritor sobrevivente Imre Kertesz, entre "uma maneira de viver deformada, tanto de nossa civilização como de nossa vida privada, e a possibilidade do Holocausto", leva a que de fato, o Holocausto não seja "nada estranho para a natureza humana". ${ }^{3}$ Isso nos alarma.

A obra da Arendt nos alerta sobre a fragilidade inerente à nossa civilização, tanto quanto às nossas democracias. Para refletir sobre este tema, ela contribui, pelo menos em três áreas, de maneira relevante, ao pensamento político:

- $\quad$ sua definição do agir politicamente como uma dimensão fundamental da existência humana, o que implica, ao mesmo tempo, em franqueza e risco;

- $\quad$ a substituição do subjetivismo e individualismo moderno por um intersubjetivismo que pauta cada relação com a realidade em uma pluralidade ativa e,

1 Ambas as organizações foram estabelecidas por Oded Grajew. A este respeito, ver: $<$ www.ethos.org.br $>$ e <www.nossasaopaulo.org.br $>$.

2 WELZER, Herald. Täter. Wie aus ganz normalen Menschen Massenmörder werden. Frankfurt: S. Fischer, 2005.

3 KERTESZ, Imre. Wem gehört Auschwitz? Eine Gedankenlänge Stille, während das Erschießungskommando neu lädt. Essays, Reinbek: Rowohlt, 1999, p. 150. 
- a definição de uma sociedade política e livre como um lugar civilizado que tem que ser sempre mantido vivo pela ação política.

Para discutir mais profundamente a nova definição de política segundo Arendt, queria concentrar-me, em seguida, em cinco pontos: o espaço público, a experiência do século XX, a distinção entre poder e violência, os riscos da política hoje e a importância da ação política responsável.

\section{O Espaço político}

Diferentemente da tradição ocidental, Arendt define política não como dominação, mas como ação. Desde Platão, segundo sua crítica, os sistemas de governo foram definidos como sistemas de dominação nos quais ou uma pessoa reina sobre todas, ou poucos sobre muitos ou todos sobre si mesmo. A definição de política como ação, ao contrário, elimina esta divisão e coloca em questão os fenômenos daí decorrentes: as hierarquias e exclusões e também a equiparação entre política e violência. Não são indivíduos ou grupos que dominam, senão pessoas que atuam, relacionando-se umas com as outras. Como retificação quase antropológica em favor de uma visão aberta e horizontal de política, Arendt emprega o termo pluralidade. Para ela, a pluralidade não significa desde uma tolerância passiva até à indiferença, mas uma inter-humanidade positiva como única possibilidade de "ser no mundo". No seu livro $A$ Condição Humana, com as definições ideal-típicas de labor, trabalho e ação, ela descreve esta relação com o mundo, que tem lugar pelo falar e pelo agir conjuntamente e que somente se deixa aparecer pela relação intersubjetiva, a demonstrarem as particularidades de cada sujeito, todos diferentes entre si.

Arendt não somente opõe este intersubjetivismo ao subjetivismo e ao individualismo moderno, como também critica o acosmismo tendencial de nosso subjetivismo, o que é, sem dúvida, favorecido por nós nos dias de hoje. Numa carta a Karl Jaspers, seu segundo professor, ao lado de Heidegger, ela escreveu que o mal dos acontecimentos recentes ,tem a ver, de qualquer maneira, com os seguintes fenômenos: fazer os homens, em sua pluralidade, supérfluos. Tudo isso nasce, ou melhor dito, está ligado à alucinação de onipotência do homem... 
Agora tenho a suspeita que a filosofia não é completamente inocente nessa trapalhada, porquanto a filosofia ocidental nunca teve um conceito do político e também, mesmo que tivesse, falava enfaticamente do homem e tratava o fato da pluralidade apenas de passagem. ${ }^{4}$

Até agora, observou-se muito pouco sobre a importância desse intersubjetivismo em Arendt. Todavia, ele não é somente decisivo para a crítica de Arendt à Filosofia, mas também para a sua crítica à Teoria Política. Mesmo tendo abandonado seu projeto de escrever um livro de introdução à política em favor de outros temas, em quase todos os demais trabalhos, o aspecto do intersubjectivismo está presente ao longo de sua obra: esteve presente desde a descrição da relação com o mundo intersubjetivo, passando pelo federalismo como constituição política da pluralidade até o diálogo interno como condição do julgamento e da consciência. Sempre descreve essa possibilidade, essa posição do entre como fundamental para a orientação no pensar e no agir a partir do que explica a redução, passo a passo, da relação com o mundo e da orientação que conduziu à ação individual instrumental inclusive violenta, ao nacionalismo e à soberania e aos sofismas do pensamento e de sua falha política e moral.

Em virtude de sua crítica do conceito tradicional de política, Arendt esboçou uma perspectiva dos fenômenos políticos, baseada na pluralidade. Assim, a liberdade já não existe na mera possibilidade de se ser livre e tampouco na liberdade tão implorada de pensar ou querer, mas somente no sucesso da ação mesma.

A liberdade, ou o seu contrário, experimenta-se com o outro e não em relação consigo mesmo. Os homens são livres diferentemente de possuírem o dom da liberdade - enquanto agem, nem antes, nem depois, pois ser livre e agir é a mesma coisa. $^{5}$

O sentido da política é a própria liberdade. Desta maneira, Liberdade e Política são idênticas, e onde não existe esta forma

4 ARENDT, Hannah; JASPERS, Karl. 1926-1969: Briefwechsel. München-Zürich, 1985. p. 202.

5 ARENDT, Hannah. O que é liberdade? In: . Entre o passado e o futuro. São Paulo: Perspectiva, 1979. p. 198. 
de liberdade, não há também nenhum sentido de espaço público. ${ }^{6}$

Arendt considera que a soberania, desde há muito tempo pensada como a mais alta essência positiva da liberdade na política externa, traduz, segundo sua perspectiva, uma atitude não dialógica, porque pressupõe a prevalência e a própria independência da vontade de cada indivíduo acima da comunidade, da associação com os outros. A soberania tem que ser recusada não pelo fato de tornar-se inibidora, num mundo de interdependências progressivas ou por estorvar a implementação dos direitos humanos, mas por contradizer a condição humana de pluralidade, de relações inter-humanas e da mundanidade que lhe é inerente. Assim é também com todos os fenômenos pré-políticos, como o nacionalismo ou quaisquer valores morais, pois eles reduzem ex-ante o espaço do falar e do agir.

Se agora o espaço político e, com ele, a política está livre de todas as ligações pré-políticas, ele precisa de durabilidade e de estabilidade em face da volatilidade, tanto quanto da imensa potencialidade da ação; o espaço político precisa de proteção, o que, politicamente falando, traduz-se na constituição. Ela possibilita e ao mesmo tempo protege este espaço. Mas isso implica também, segundo Arendt, na aceitação do dissenso e da desobediência civil frente a uma ação governamental que viola a constituição, como por exemplo, as deliberações do governo dos Estados Unidos durante a guerra de Vietnã.

\section{Experiências políticas no século $X X$}

O que nos impressiona em Arendt é sua posição enquanto uma pensadora participante, que se distingue claramente da posição de uma cientista distanciada. Recusou críticas de não haver escrito objetivamente, porque, como escreveu Arendt, descrever os campos de concentração sine

6 ARENDT, Hannah, O que é política? Rio de Janeiro: Bertrand, 1998. p. 38-39. 
ira não significa ser "objetivo" senão desculpá-los. ${ }^{7}$ Quando o historiador Golo Mann, filho de Thomas Mann, a acusou de ser exagerada, quanto aos textos de seu livro sobre o totalitarismo, ela refutou tal crítica, não com uma defesa meticulosamente preparada, e sim, retrucando:

\begin{abstract}
Exagerar - naturalmente. "Correlações de sentido" como você diz, não podem ser construídos de outra maneira. Em geral o pensar exagera sempre. ... Além disso, a realidade tem realmente abusado neste século, e o que se pode dizer, seguramente, que a realidade é exagerada. Nosso pensamento, que ama, acima de tudo, os percursos que já conhece, dificilmente pode atingi$1 \mathrm{a} .^{8}$
\end{abstract}

Todavia, participação, neste contexto, não quer dizer que Arendt e seu interesse pelo mundo se inclinasse para uma atitude moralizante, ao contrário. Para ela, tratou-se, em primeiro lugar, da compreensão dos eventos e com isso, da compreensão das experiências de todos os participantes, pois desta forma, pode-se definir as possibilidades de agir. Num retrato do poeta Bertolt Brecht, descreveu as experiências dos adolescentes desde a Primeira Guerra Mundial, para quem o seu até então seguro mundo foi sacudido abruptamente. Foram experiências do que se pode chamar de "gerações perdidas", e atestam sobre os riscos da liberdade, que Arendt afirmou serem permanentes. Somente a ação política e a responsabilidade pelo espaço público comum podem evitar a ruína.

Arendt discorreu sobre três de tais gerações perdidas: aquela de Brecht, "cuja iniciação no mundo foram as trincheiras e os campos de batalha da Primeira guerra Mundial", e que, chegado o tempo de paz, simulou que nada se passara. Dez anos mais tarde, a geração da República de Weimar, à qual Arendt pertenceu, cujo cepticismo foi o denominador comum; e a terceira, também dez anos mais tarde, na segunda década do século XX,

7 Kontroverse Ansichten: Der Disput zwischen Hannah Arendt und Eric Voegelin über das Totalitarismusbuch (1953). In: Über den Totalitarismus. Texte Hannah Arendts aus den Jahren 1951 und 1953. Dresden: Hannah-Arendt-Institut für Totalitarismusforschung, 1998. p. 45.

8 ARENDT, Hannah; JASPERS, Karl. 1926-1969: Briefwechsel. München-Zürich, 1985.

9 ARENDT, Hannah. Bertold Brecht. In: Homens em tempos sombrios. São Paulo: Companhia das Letras, 1996. p. 186. 
"que teve a opção de se iniciar no mundo entre os campos de concentração nazistas, a guerra civil espanhola e os processos de Moscou." 10

Arendt escusou que muitos dos membros dessas gerações não viriam a ser democratas porque suas possibilidades de agir foram muito limitadas. Citou como exemplo, o caso de um trotskista que respondeu a sua pergunta sobre as razões de seu engajamento político no princípio dos anos trinta, afirmando que lutara menos por questões gerais como justiça ou liberdade, mas por estar preocupado consigo mesmo.

Ao invés vez de uma resposta direta, contou-me uma história, a história de um jogador habitual de jogos de azar que casualmente, chegou a uma cidade estranha já tarde e, naturalmente, dirigiu-se imediatamente a um lugar de jogo. Aí uma pessoa da localidade o alertou que a roleta estaria sendo manipulada, ao que o estrangeiro respondeu: "Mas não tem outra roleta na cidade." A moral da história era, conforme o meu conhecido quis dizer que naqueles dias quando, alguém queria fazer algo a todo o custo, não podia fazê-lo senão aonde houvesse um lugar apropriado para jogar roleta; não ia ali pelo bem da sociedade em geral, mas por si próprio. ${ }^{11}$

Arendt realizou, em 1955, seminários sobre a temática "Experiências políticas no século XX", concentrando-se na experiência de um homem que, segundo sua citação, podia ser considerado um ideal-tipo que vivenciou o século XX e para quem "os acontecimentos, assim como se passaram, foi como uma chuva que caiu inesperadamente sobre ele, o que levou a uma determinada reação". Esse homem ideal-típico nasceu em 1890 e foi provavelmente um francês. Participou da Primeira Guerra Mundial e tornou-se o "soldado desconhecido". Depois disto, quis mudar o mundo pela esquerda ou pela direita, transformando-se em um soldado profissional e terminando por se submeter a uma das formas de domínio totalitário que, apesar dos campos de concentração, exerciam nele uma certa forma

10 ARENDT, Hannah. Bertold Brecht. In: Homens em tempos sombrios. São Paulo: Companhia das Letras, 1996. p. 187.

11 ARENDT, Hannah. Action and "The Pursuit of Happiness". In: DEMPF, A; ARENDT, H; ENGEL JANOSI, F. (Orgs.). Politische Ordnung und menschliche Existenz. Festgabe für Eric Voegelin. München: Beck, 1962, p. 4. 
de atração. À diferença da Primeira Guerra Mundial, pareceu-lhe razoável participar na Segunda Guerra Mundial ao lado dos aliados ou da resistência. Depois disto, tornou-se um filósofo da rebelião, como Camus, ou do engajamento, como Sartre. De ambas as guerras mundiais, resultou um mundo único no qual a diferença entre política interior e exterior torna-se mais e mais irreal. E, nos países desenvolvidos, surgiu a sociedade de massas, além de invenções de científicas como a bomba atômica, capaz de destruir a humanidade inteira.

Para Arendt, estes seminários serviram como exercícios de imaginação, como condição para qualquer julgamento. Por isso, quase não usava uma literatura politológica, senão testemunhos literários, memórias e ensaios. $^{12}$

Ao tematizar as possibilidades limitadas de ação a partir das experiências de uma geração perdida e de uma tradição oculta de liberdade política, a qual aquela geração não conheceu, ela questionou, ao mesmo tempo, a fragilidade da ação e as pré-condições para um pensamento livre e humano. Sob as condições extremas do domínio totalitário, a responsabilidade política já não seria possível, porque "somente aqueles que se retiraram completamente da vida pública e recusaram toda forma de responsabilidade política puderam evitar ser enredados em crimes políticos. ${ }^{13}$ Quedou somente a possibilidade de julgar em diálogo consigo mesmo, ou seja, de tomar uma posição de dúvida e cepticismo, porque somente se pode assumir a responsabilidade pelo mundo quando se dispõe "de um mínimo de poder político"14. Mas, para isso, necessita-se de liberdade e de sua constituição, para que se possa reunir-se e organizar-se. Somente assim as pessoas podem construir este minimum de poder, e somente aí surge o que Arendt caracteriza tão enfaticamente como espaço público, como o espaço do aparecer. Este espaço somente pode existir se as pessoas de fato o constroem, ele somente está ali onde pessoas agem em conjunto e constroem este poder.

12 ARENDT, Hannah. Political experiences in the twentieth century. Notes, 1955, inédito, Library of Congress, Washington D.C.

13 ARENDT, Hannah. Persönliche Verantwortung in der Diktatur. In: Israel, Palästina und der Antisemitismus. Berlin: Eike Geisel e Klaus Bittermann,1991, p. 24.

14 Ibid., p. 35. 


\section{Poder e violência}

Mas o que é o poder? Para Arendt, é surpreendente que, num século como o foi o século passado, de violência, com duas guerras mundiais, passando pelo Holocausto, as guerras coloniais e de libertação, assim como um movimento estudantil violento que "tal violência raramente seja escolhida para considerações especiais." ${ }^{15}$ De uma perspectiva intersubjetiva poder e violência se diferenciam tão explicitamente como mundanidade e acosmismo, ou o falar e o calar-se. Tampouco a famosa fórmula de Max Weber, do Estado enquanto "o domínio do homem pelo homem por meio da violência legítima" como verdade óbvia das ciências políticas, permite conhecer a particularidade do poder, o seu potencial para a liberdade. Essa particularidade se encontra na "capacidade humana não somente de agir, mas de agir de comum acordo". ${ }^{16}$

Para Arendt,

[...] poder precede e dura mais do que qualquer meta, de tal modo que o poder, longe de ser um meio para atingir um fim, é, na verdade, a própria condição que permite a um grupo de pessoas pensar e agir conforme a categoria dos meios-fins. ${ }^{17}$

Ele pertence "à essência de toda comunidade estatal" e a estrutura de poder se encontra "antes de todos os fins e sobrevive a eles", enquanto que violência não pertence à essência das comunidades estatais; "ela é, por natureza, instrumental, é um meio para se chegar a um fim, mas inclina-se a transformar-se num fim em si mesma e perde sua plausibilidade quando seu fim se perde." ${ }^{\prime 18}$

O papel do poder se mostra em conflitos violentos que, no final, não se decidem pelo potencial de violência, mas pelo poder, ou seja, pelo crescimento ou pela perda de consentimento em ambos os lados. Assim a

15 ARENDT, Hannah. Da violência. In: Crises da república. São Paulo: Perspectiva, 1999. p.

97.

16 Ibid., p. 116, 123.

17 Ibid., p. 130.

18 Ibid., p. 130-131. 
invasão da União Soviética à Tchecoslováquia em 1968 destruiu, de fato, a primavera de Praga, mas custou todo apoio futuro para a União Soviética e com isso o poder.

"Substituir o poder pela violência pode trazer a vitória, mas a um preço muito alto, que não é apenas pago pelo vencido, mas também pelo vencedor em termos de seu próprio poder" (ARENDT, 1999). E com respeito à política dos Estados Unidos no Vietnã, Arendt adita: "Isto é especialmente verdade quando o vencedor desfruta internamente das bênçãos de um governo constitucional." 19

Quando o meio para um fim torna-se um fim em si mesmo não somente o poder está perdido senão também a política. Entretanto, não é preciso chegar a este ponto para falar dos riscos na política. Porque no momento em que o pensamento em termos de meio-fim domina a política, perde-se o poder. Este pensamento nasce da força sedutora que exerce uma política que esteja orientada pela realização de certos fins, como a revolução, a nova ordem geopolítica, a intervenção armada para o estabelecimento de uma nova ordem social, etc.. Onde quer que se pratique um ato para alcançar um fim superior, o acepilhamento, a violência penetra na política e a desfigura.

Ao distinguir desta maneira as relações entre poder e violência, Arendt conclui que o contrário de violência não é a não-violência, senão o poder, quer dizer, não a questão da seleção de meios, senão a própria política.

Política e ação política, descritas por Arendt, distinguem-se de "processos e procedimentos de rotina", de "um mundo onde nada de importante acontece" 20 , porque qualquer ação afeta ou interrompe um comportamento previsível. Ação política é a única capaz de interromper tais processos, mas ela depende da manutenção do espaço da pluralidade. Ao definir, de forma precisa, que a liberdade somente existe quando se age, e somente aí onde existe poder em lugar de violência e federação em lugar de soberania, o pensamento político de Arendt representa um alarme explícito sobre os perigos de uma sociedade apolítica. O espaço político não nasce, natural-

\footnotetext{
19 ARENDT, Hannah. Da violência. In: Crises da república. São Paulo: Perspectiva, 1999. p.

20 Ibid., p. 97.
} 131. 
mente, da natureza, mas é um resultado cultural, uma construção que tem de ser sempre reavivada.

Discussões como ocorreram na Alemanha há dois anos, sobre o uso da tortura pelo estado em casos excepcionais, como por exemplo, o caso do seqüestro de uma criança, são terríveis mas, ao mesmo tempo, necessárias para assegurar-se novamente, os fundamentos civilizados das nossas comunidades.

Todas as instituições políticas são manifestações e materializações de poder; petrificam e decaem quando o poder vivo do povo cessa de lhes sustentar. Era isto o que Madison queria dizer com ,todos os governos repousam na opinião. ${ }^{21}$

Deixar as coisas ao sabor delas mesmas resulta, seguramente, na ruína da política, da civilização e também da cultura.

\section{Perigos para a política}

O espaço político não se perde somente quando se estabelece uma tirania, mas já no momento em que a liberdade não está preenchida com a vida da ação em sua espontaneidade, quando o julgamento independente cede lugar às deduções lógicas e, o pensamento, ao não pensar. Tomemos o exemplo da era McCarthy nos Estados Unidos dos anos cinq6enta, quando, devido ao policiamento, à censura, ao desmesurado uso da mentira na política e à guerra de Vietnã, este risco de perda se fez presente, causando uma profunda inquietação em Arendt.

Para além da distinção entre poder e violência, também a questão da relação com o mundo (comprometimento ou indiferença) nos fazem abrir os olhos para a fragilidade das repúblicas atuais. Não se trata somente de weak states ou estados débeis, nos quais qualquer ordem política se vê na

120.

21 ARENDT, Hannah. Da violência. In: Crises da república. São Paulo: Perspectiva, 1999. p. 
iminência de perder-se em favor do domínio da violência, de perder para os senhores da guerra (war-lords), mas por formas mais sutis de dominação por parte dos estados supostamente mais fortes. Para Arendt, debilidade ou força não são definíveis apenas pelo número de meios ou instrumentos de violência existentes ou pela intensidade concreta do domínio, senão pela efetividade dos elementos fundamentais da república, como o efetivo respeito às leis, a divisão dos poderes e o controle mútuo entre eles, bem como a garantia efetiva das liberdades e direitos.

Exemplos como os Estados Unidos no tempo de Bush Jr., a Venezuela de Chavez e o Brasil após 20 anos de redemocratização ilustram a fragilidade a que se expõem as repúblicas.

Iniciemos com os Estados Unidos: a política externa hegemônica deste país não desrespeita somente os acordos internacionais, mas prejudica sua própria reputação, e, com isso, seu próprio poder internacional no sentido atribuído por Arendt; sobretudo, ela é prejudicial para as instituições republicanas. A já mencionada afirmativa de Arendt, de que uma vitória a todo custo conduz à perda do poder, foi comprovada no caso da guerra do Iraque, pela ausência de uma oposição no congresso, pelo silêncio prolongado da justiça sobre a situação jurídica em Guantânamo e a pela degradação do direitos civis nos Estados Unidos.

A prepotência do poder executivo sobre os outros poderes que deriva deste procedimento não conduz a um aumento real do poder, ao contrário, ao seu enfraquecimento. "É tentador argumentar", escreve Arendt num ensaio sobre a mentira na política,

[...] que o presidente, supostamente o mais poderoso homem do mais poderoso país, é a única pessoa deste país cuja possibilidade de escolha pode ser predeterminada. Isto naturalmente só pode acontecer se o poder executivo se afastou do contato com os poderes legislativos do Congresso; é o resultado lógico no nosso sistema de governo em que o senado está sendo privado, ou reluta em exercer, seus poderes de participação e assessoramento na conduta de assuntos externos. $^{22}$

22 ARENDT, Hannah. A mentira na política. In: Crises da república. São Paulo: Perspectiva, 1973. p. 18. 
Não está em causa apenas, como escreve o historiador Arthur Schlesinger Jr., "a ameaça interna do equilíbrio constitucional que nasce da área da política externa" quanto mais aguda for a crise ${ }^{23}$, senão a perda do senso de realidade que acompanha tal desenvolvimento, minando a república. Isto levou o jornalista Jonathan Schell a caracterizar o congresso republicano dos Estados Unidos, antes da reeleição de George W. Bush em 2004, como "proto-totalitário", "um convite para um povo ainda livre não somente a acreditar em algumas mentiras, mas também a acreditar no que ela denominou (Arendt, WH) como um mundo mentiroso". ${ }^{24}$

Enquanto não ocorrer a necessária divisão entre os poderes conforme a descrição Arendt, e a relação com o mundo, bem a como a diferença mais transcendente entre poder e violência, a fragilidade da república norte-americana dificilmente será suplantada.

No que diz respeito ao caso da Venezuela: ali também ocorreu uma grave desestabilização do poder político em virtude da preponderância do poder executivo, disfarçado de um populismo radical-democrático. Com a mudança da constituição em 1999, o poder legislativo e o poder judiciário foram debilitados, ao se juntarem os cargos de chefe de estado com o de chefe de governo; dissolveu-se a segunda câmara do parlamento dos 23 estados federais e Chavez governou, em questões de nacionalização, duas vezes até agora, com decretos-lei, prescindindo da intervenção parlamentar. Suportou conscientemente as agitações e adversidades populares ${ }^{25}$ e deu prosseguimento à política de concentração de poder em suas próprias mãos, o que se reflete na tentativa de criação de um partido único e no fechamento do canal de televisão RCTV, no ano de 2007. Como no caso de Bush, a fachada do chefe de um governo forte é o avesso de uma república, a qual se encontra, na verdade, debilitada.

Governos populistas não são uma raridade nos moldes da chamada terceira onda de democratização dos anos 80 do século passado. Repre-

23 SCHLESINGER JR., Arthur. The imperial presidency Redux. In: War and the Amercian Presidency. New York: W.W. Norton \& Co, 2004. p. 45.

24 SCHELL, Jonathan. Letter From Ground Zero: The Grand Illusion. The Nation, September, $27,2004$.

25 BOECK, Andreas. Venezuela auf dem Weg zu einem autoritären Neopopulismus? Welt Trends, 29, p. 79-96, 2000/2001; GRATIUS, Susanne. Venezuela: Staatszerfall in einem polarisierten Land. In: SCHNECKENER, Ulrich. States at risk. Fragile Staaten als Sicherheits: und Entwicklungsproblem. Berlin: SWP, 2004, p. 84-104. 
sentam o desejo generalizado de governos fortes em vencer problemas graves como a pobreza, a corrupção e a desigualdade. A ligação de um poder executivo poderoso com o "povo" caracteriza democracias illiberais ou anti-liberais ${ }^{26}$, cujas tendência ao aumento ilimitado de funções (a hipertrofia do executivo), mina a sua estabilidade, enquanto que a limitação do poder estabiliza o poder por checks and balances, elemento intrínseco à república.

Em outros países, como é o caso do Brasil, a efetividade da república está minada pela corrupção, violência e criminalidade organizada, bem como a paulatina fragmentação da sociedade. Em São Paulo, no ano de 2006, a organização mafiosa PCC se elevou à categoria de parceiro de negociação do governo por meio de atentados contra estabelecimentos públicos. Este, como outros casos, mostram que a inatividade na política, o não agir, conduz à depravação da política e à desaparição do espaço político.

Finalmente, cabe mencionar o exemplo da Itália na década passada, quando a destruição da esfera política pelos próprios partidos foi continuamente praticada, chegando até a sua dissolução, no início dos anos 90, pela anti-política de Berlusconi, que comprou em grande estilo a justiça e congelou as atividades parlamentares. ${ }^{27}$

\section{Responsabilidade e virtuosidade}

Estamos a nos enganar quando evitamos discutir sobre a importância da ação política em uma sociedade que funciona segundo o modelo político-burocrático. Basta dar uma olhada para as regiões em crise para se concordar sobre a relevância não somente da estrutura das instituições republicanas, como também para a necessidade da ação política.

Desde os anos oitenta, a pesquisa científica acompanha a chamada terceira onda de democratização. Sobre este tema, ela tem em mira, primeiramente, a transição à democracia que, nos anos noventa, implicou na sua

26 ZAKARIA, Fareed. The future of freedom: illiberal democracy at home and abroad. New York: W.W. Norton \& Co., 2003.

27 STILLE, Alexander. Citizen Berlusconi, the sack of Rome: how a beautiful European country with a fabled history and a storied culture was taken over by a man named Silvio Berlusconi. Rutherford: The Penguin Press HC, p. 200. 
institucionalização, o que se convencionou chamar de institution building, e pouco depois, como questões de boa governança ou Good Governance. Entretanto, as dificuldades de consolidação da democracia passam para o primeiro plano: deficiências no processo de eleição dos representantes, a imposição insuficiente das leis civis e da liberdade, o controle ineficaz das ações do governo, os espaços sem leis - todos estes são problemas de uma "democracia com defeitos". ${ }^{28} \mathrm{O}$ mero apelo para fortalecer a separação de poderes e de se eliminar a corrupção e os espaços sem leis são de pouco alcance. Igualmente insuficiente é a descrição que a descrição de uma "democracia consolidada" 29 , como aquela que dispõe de uma sociedade civil com a liberdade de assembléia, de uma sociedade política livremente eleita, do domínio das leis, de um aparelho de estado com suas normas de administração racional e, finalmente de um mercado livre institucionalmente assegurado. Em todas estas análises, falta o elemento da ação, cuja importância numa democracia perfeita é evidente.

Nem as teorias da sociedade civil, que delimitam as relações entre a sociedade e o estado, nem a boa governança, que parte de uma democracia consolidada e implicitamente de uma ação débil, retomam este aspecto arendtiano da ação. Nem mesmo as teorias de um republicanismo que associam um engajamento da cidadania com um pathos do senso comum político e um catálogo de virtudes políticas, correspondem às intenções de Arendt. Ainda que se possam observar algumas semelhanças entre estas tendências interpretativas e as de Arendt, é necessário ressaltar que Arendt jamais elaborou qualquer conceito de política contra o estado, ou esboçou qualquer imagem do que pudesse vir a ser uma boa governança e tampouco um modelo baseado em uma república de virtudes. O seu conceito de política não está baseado em critérios morais e tampouco prosseguindo fins superiores, mas no entendimento da ação política como fim em si mesmo e como expressão de pluralidade e mundanidade; para Arendt, o espaço político fica aberto e submetido à condições mudandas da ação e de suas possibilidades.

28 MERKEL, Wolfgang et al. Defekte Demokratie, Bd. 1: Theorie, Opladen: Vs Verlag für Sozialwissenschaften 2003; Defekte Demokratie, Bd. 2: Empirische Analysen, Opladen: Vs Verlag für Sozialwissenschaften, 2004.

29 LINZ, Juan; STEPAN, Alfred. Toward consolidated democracies. Journal of Democracy, v. 7, n. 2, p. 14-33, April, 1996. 
Para Arendt, a responsabilidade política não é uma categoria moral nem uma categoria republicana de um interesse prioritário acerca do bem comum, mas uma categoria existencial. Mesmo que Arendt confronte o espaço político com o acosmismo, a ação política não é uma obrigação moral, como se fosse um sacrifício para o nascimento e manutenção do espaço político; ela é antes e acima de tudo uma atividade que nasce da espontaneidade e do deliciar-se na ação. Por isso, responsabilidade tem de ser compreendida como resposta existencial aos desafios do tempo, como o interesse pelo outro; como a abertura para mais além dos interesses privados, para os assuntos comuns num mundo comum, como uma ação que pressupõe a disposição para tolerar situações constrangedoras, porque somente a vida comum e pública parece, ao fim e ao cabo, valer a pena de ser vivida.

Aqui se destacam três paradoxos inerentes a este conceito de política. O primeiro paradoxo reside na necesidade de agir que, no entanto, não pode ser uma imposição. Por mais que liberadade e política, segundo Arendt, somente possam residir na ação mesma, dependendo assim do engajamento dos que agem, esse agir se baseia no prazer de agir e não no sacrifício. Não por acaso Arendt se refere ao prazer do agir, visível em todos momentos em que ocorrem ações espontâneas, criativas e "salvadoras". As motivações para tal agir não se encontram no ressentimento ou numa moral superior, mas na justiça política e no reconhecimento. Assim, perdura sempre a esperança de que em tempos de crise e de ausência de perspectivas, possam ser encontrados homens e mulheres que sobem ao palco para agir.

Por isso, pessoas que agem, desempenham um papel importante, pois, conforme Arendt.

A ação é sempre também um exemplo. Pensar e julgar politicamente é exemplar (Kant), porque agir é exemplar. Responsabilidade quer dizer essencialmente que se coloca um exemplo para outros seguirem, mudando, desta forma, o mundo. ${ }^{30}$

A este mundo de pessoas que oferecem exemplos pertence Maquiavel, sobre quem, a autora afirma: "Com respeito a Maquiavel, eu 
sempre tive uma inclinação de enamorar-me dele". ${ }^{31}$ Também Lessing, "que nunca se reconciliou com o mundo em que viveu. Comprazia-se em desafiar preconceitos e contar com a verdade aos apaniguados da corte". ${ }^{32}$ Rosa Luxemburg, "para quem o mais importante era a realidade, em todos os seus aspectos medonhos e maravilhosos, mais ainda do que a própria revolução". ${ }^{33} \mathrm{E}$, Waldemar Gurian - um amigo, reitor da Universdade de Notre Dame, nos Estados Unidos, ao afirmar que toda existência espiritual era baseada na decisão de nunca conformar-se e nunca fugir, o que expressa exatamente aquilo que pode-se chamar de coragem". ${ }^{34}$

Todos revelam o que se chama em Inglês public spirit. Esse espírito público não pode ser substituído por um conceito de sociedade ideal. Isso se refere ao segundo paradoxo, que consiste no fato de que o pensamento de Arendt sobre política e agir pareça sugerir a imagem de uma sociedade futura. No entanto, Arendt renuncia, por boas razões, a tal imagem, pois em seu pensamento, política e liberdade são indetermináveis e estão sempre expostas ao risco de se falhar. O estabelecimento de uma sociedade ideal destrói a liberdade como o demonstraram os experimentos da era moderna. De semelhante modo, a tentativa de proteger a liberdade por parte da sociedade liberal, de maneira administrativa, conduz a uma não livre biopolítica e uma não livre política de população, como foi descrito por Michel Foucault. ${ }^{35}$

Finalmente: O que significa a "amizade política", já que o título desta palestra é Amizade política pelo cuidado com o mundo?

Trata-se da responsabilidade pelo mundo, não somente o mundo da natureza, do meio ambiente, do aquecimento do clima etc., mas, sobretudo o mundo que temos em comum com os outros homens, pelas relações, no falar e no agir. Este mundo é público e é o lugar das relações com o

31 a Dolf Sternberger, 27.12.1973, correspondência inédita.

32 ARENDT, Hannah. Sobre a humanidade em tempos sombrios: reflexões sobre Lessing. In: Homens em tempos sombrios. São Paulo: Companhia das Letras, 1996. p. 15.

33 ARENDT, Hannah. Rosa Luxemburg. In: Homens em tempos sombrios. São Paulo: Companhia das Letras, 1996. p. 42.

34 ARENDT, Hannah. Waldemar Gurin. In: Mernhen in fisnteren Zeiten. München: Piper, 1989 , p. 323.

35 A este respeito, ver: FOUCAULT, Michel. A governamentalidade. In: Microfísica do poder. Rio de Janeiro: Graal, 1979, p. 277 et seq.; FOUCAULT, Michel. Em defesa da sociedade. São Paulo: Martins Fontes, 1999. 
mundo. Carecemos deste mundo comum como único lugar da civilização. Toda a briga política teria que ser conduzida pela consciência que esse mundo nos une e que o fosso essencial não se encontra entre nós, mas entre nós e a barbárie, desde que os cidadãos sejam amigos no sentido de terem interesse na preservação do mundo comum. Não são amigos íntimos, mas públicos, como já afirmou Aristóteles: "É o espírito público que é necessário para dar vida às instituições":

A amizade mantém unidas as comunidades da polis e os legisladores se esforçam mais por ela do que pela justiça, porque a concórdia tem evidentemente certa semelhança com a amizade. [...] "Quando os cidadãos são justos, além da justiça, eles apreciam ainda mais a amizade, e o grau mais elevado de um ser justo mostra sinais visíveis da amizade". ${ }^{36}$

Então, mover-se neste mundo implica que todos estes fenômenos, como ação e responsabilidade política e senso comum se baseiem na amizade, nas relações com os outros e na atenção e respeito para com suas visões e opiniões. Mas temos que saber que nem todos querem ser amigos dos que representam o espírito público.

Isto nos conduz ao terceiro paradoxo, que reside no fato de que, mesmo numa sociedade que garanta a todos os direitos políticos, não se pode garantir que todos tenham interesse no bem estar comum e que ajam pelo cuidado com o mundo. E, ainda que se relacionassem com este propósito, eles estariam a representar opiniões contraditórias, muito distantes um do outro, desenvolvendo uma política em franco dissenso. Afinal, pessoas como Arendt e Bush Jr pertencem à mesma comunidade política, cuja liberdade querem, em princípio, defender, mas, no caso de Bush Jr, suas posições e ações provocam a destruição da própria liberdade e do próprio espírito público.

Depende de nossa capacidade de reconhecer tal paradoxo, quando e se nós quisermos manter e defender esta comunidade. 